\title{
Perobahan dimensi hasil cetakan alginat berbentuk balok
}

\author{
Sumadhi Sastrodihardjo \\ Departemen Ilmu Material dan Teknologi Kedokteran Gigi \\ Fakultas Kedokteran Gigi Universitas Sumatera Utara \\ Medan, Indonesia
}

\begin{abstract}
There are several causal possibilities developing dimensional changes on impression such as type of impression materials used, impression taking technique, bulk of impression material or size of impression tray. In this study investigation was done on the size of impression material used to elucidate the possibilities role of impression material in gaining dimensional changes of impression. Rectangle shape alginate impressions were made in $29.57 \mathrm{~mm}$ length, $19.45 \mathrm{~mm}$ width and $9.67 \mathrm{~mm}$ thickness mold of metal master die covered by glass plate and dimensional changes are measured on alginate impression itself. Then data were analyzed with T-test (paired samples test) to compare dimension changing between alginat height and dimension changing on length and width. Measured results show the dimensional changes occur $3.16 \% \pm 0.63 \%$ on length side, $3.35 \% \pm 0.42 \%$ on width side and $10.87 \% \pm 1.01 \%$ on thickness side, respectively. There are significantly differences of dimensional changes on thick ness side covered by glass plate compared with dimensional changes on length and width sides surrounding by metal of master die.
\end{abstract}

Key words : Impression, dimensional changes.

\begin{abstract}
ABSTRAK
Perubahan dimensi pada hasil cetakan dapat disebabkan oleh beberapa hal, seperti jenis bahan cetak yang dipergunakan, cara pengambilan cetakan, ketebalan bahan cetak, atau ukuran sendok cetak dan lain sebagainya. Pengamatan kali ini dilakukan langsung pada bahan cetak yang dipergunakan untuk mendapatkan kemungkinan peran yang terdapat pada bahan cetak dalam menyebabkan perobahan dimensi hasil cetakan. Balok alginat dibuat pada master die logam dengan ukuran panjang 29,57 $\mathrm{mm}$, lebar 19,45 $\mathrm{mm}$ dan tebal 9,67 mm dengan lempengan kaca sebagai penutup. Perobahan dimensi langsung diukur melalui ukuran alginat hasil cetakan. Data kemudian dianalisis dengan $T$-test (paired samples test) untuk membandingkan perobahan dimensi pada tebal/tinggi balok alginat dengan perobahan dimensi yang terjadi pada panjang dan lebarnya. Dari hasil pengukuran didapatkan perobahan dimensi masing-masing sebesar $3,16 \% \pm 0,63 \%$ pada panjang, $3,35 \% \pm 0,42 \%$ pada lebar dan $10,87 \% \pm 1,01 \%$ pada tebal balok alginat. Dari hasil pengamatan ini terlihat adanya perbedaan signifikan perobahan dimensi pada tebal balok alginat dengan penutup lempengan kaca dibandingkan dengan perobahan dimensi pada panjang dan lebar balok alginat yang dikelilingi logam master die.
\end{abstract}

Kata kunci: Cetakan, perubahan dimensi.

Koresponden: Sumadhi Sastrodihardjo, Jl. Lizadri Putra 52, Simpang Selayang, Departemen Ilmu Material dan Teknologi Kedokteran Gigi Fakultas Kedokteran Gigi Universitas Sumatera Utara, Medan, Indonesia

\section{PENDAHULUAN}

Terjadinya perobahan dimensi pada hasil cetakan akan menyebabkan ketidaktepatan ukuran model atau die dan akan menghasilkan restorasi yang tidak sesuai. ${ }^{1}$ Perobahan dimensi ini dapat disebabkan oleh banyak hal seperti jenis bahan 
cetak, ${ }^{2-4}$ cara pengambilan cetakan, ${ }^{5-7}$ ketebalan bahan cetak atau ukuran sendok $\operatorname{cetak}^{8,9}$ atau bahan die/model yang dipergunakan ${ }^{10,11}$ dan lain sebagainya. Pengamatan perobahan tersebut di atas umumnya dilakukan dengan mengukur gips model/die yang diperoleh dari hasil cetakan. Pengamatan tersebut dapat menjadikan bias hasil pengukuran dengan dilakukannya pengukuran pada gips, walaupun Rusfian $\mathrm{dkk}^{12}$ telah menunjukan kecilnya peran gips/die dibandingkan dengan peran bahan cetak dalam menyebabkan perobahan dimensi pada hasil cetakan. ${ }^{12}$ Dari semua kemungkinan penyebab terjadinya perobahan dimensi yang telah dikemukakan di atas belum satupun dapat menyingkapkan mekanisme terjadinya perobahan dimensi pada hasil cetakan.

Pengamatan perobahan dimensi hasil cetakan ini dilakukan langsung pada bahan cetak yang dipergunakan dan diharapkan dengan demikian dapat menghilangkan bias yang mungkin terjadi pada hasil pengukuran bila dipergunakan bahan model/die. Pengamatan ini bertujuan untuk melihat perobahan dimensi yang terjadi pada bahan cetak yang dicetakan dalam bentuk balok dengan ukuran tertentu. Selain dari pada untuk melihat perobahan dimensi pada bahan cetak tersebut pengamatan ini bermanfaat untuk mengetahui ketepatan hasil cetakan bila bahan cetak tersebut dipergunakan dalam pengambilan cetakan.

Dalam makalah ini akan dipaparkan mengenai hasil pengukuran langsung pada bahan cetak alginat yang dicetakkan dalam bentuk balok pada master cast dengan desain tertentu dan didiskusikan kemungkinan penyebab terjadinya perobahan dimensi tesebut.

\section{BAHAN DAN METODE}

Bahan cetak yang dipergunakan dalam pembuatan balok bahan cetak adalah irreversible hydrocolloid, alginat merk Prima Last batch no. 2005020301.

Master cast dengan desain tertentu seperti terlihat pada gambar 1 mempunyai cerukan dengan ukuran panjang 29,57 mm, lebar 19,45 $\mathrm{mm}$ dan ketinggian/kedalaman 9,67 $\mathrm{mm}$ dipergunakan sebagai mold untuk mendapatkan balok bahan cetak alginat. Sebagai penutup master cast dipergunakan lempengan kaca dengan ukuran sekitar 9 x $9 \mathrm{~cm}$ dan ketebalan kaca $5 \mathrm{~mm}$.

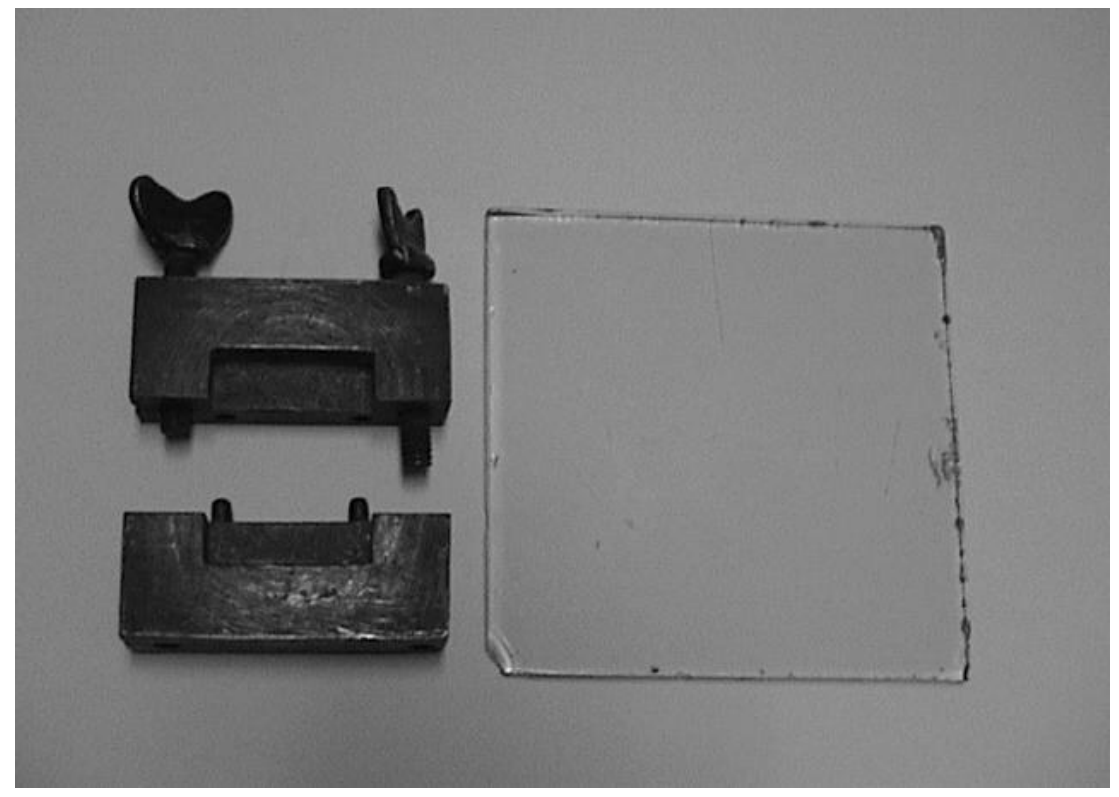

Gambar 1. Master cast yang dipergunakan 
Alginat diaduk dalam air dengan rasio $\mathrm{P} / \mathrm{W}$ 3,2 gr/6 ml dan adonan alginat dimasukkan ke dalam mold dari master cast sampai penuh, ditutup dengan lempeng kaca dan ditekan dengan mempergunakan alat press (gambar 2) sampai berhenti dan dibiarkan selama 5 menit sampai bahan cetak alginat tersebut setting.
Balok alginat yang telah mengalami setting dikeluarkan dari master cast dan pengukuran langsung dilakukan pada balok alginat dengan mempergunakan mistar ingsut digital (Digimatic caliper) merk Mitutoyo, Jepang (gambar

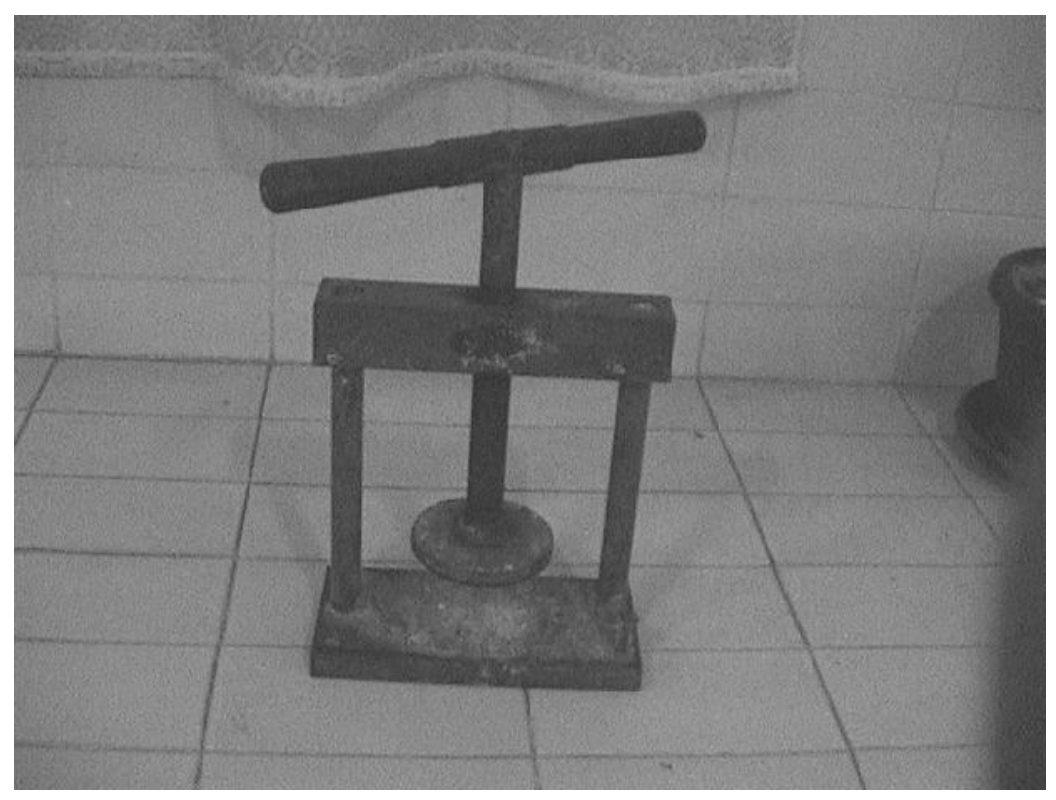

Gambar 2. Alat pres yang dipergunakan

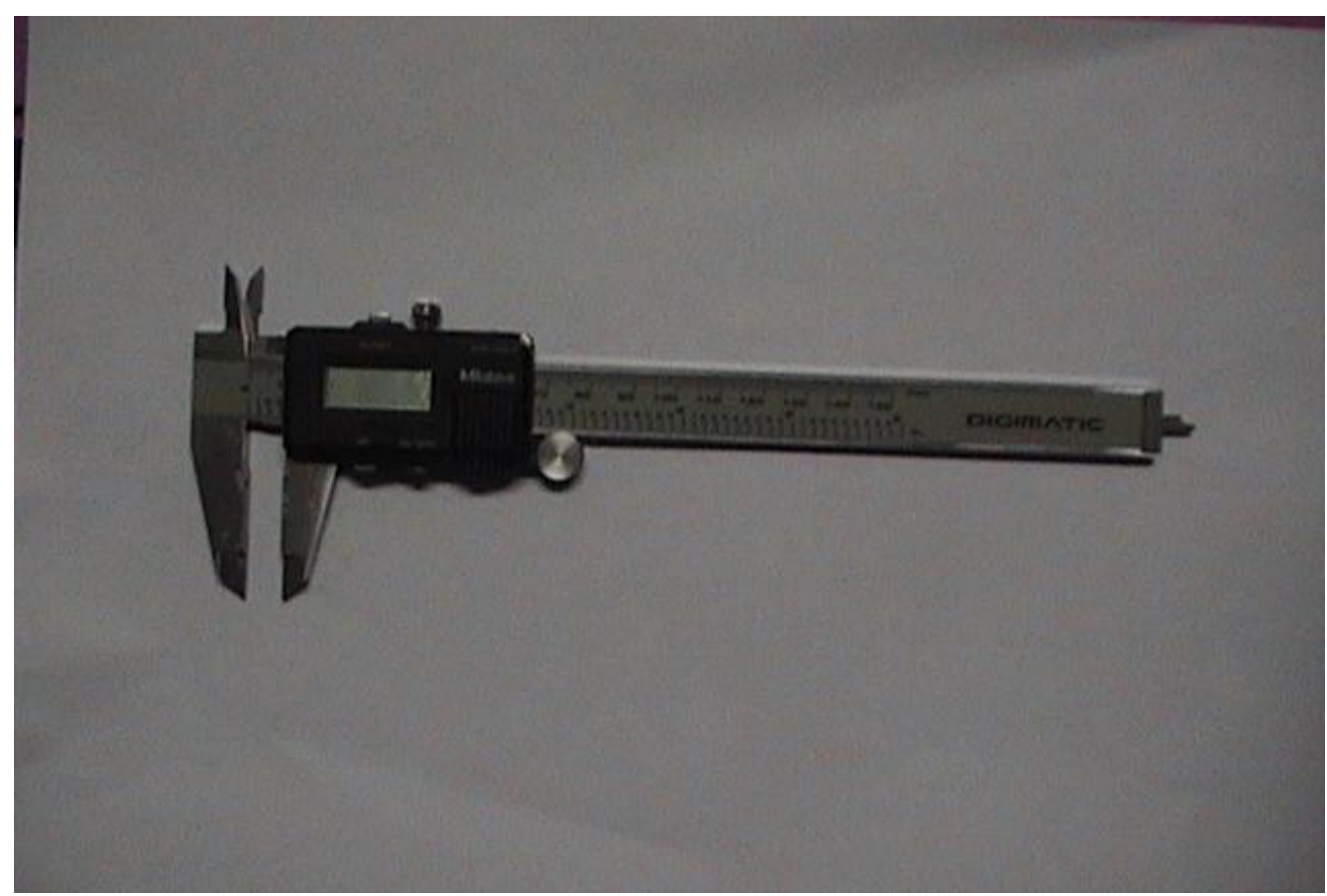

Gambar 3. Alat ukur mistar ingsut digital yang dipergunakan 
Pengukuran dilakukan pada daerah panjang, lebar dan tinggi/tebal balok alginat yang dibuatkan 10 buah balok alginat. Perobahan dimensi yang terjadi merupakan perbedaan hasil pengukuran balok alginat dengan ukuran cerukan/mold dari master cast. Perhitungan statistik dilakukan dengan mempergunakan $T$-test (Paired Samples test) untuk membandingkan perobahan dimensi pada tebal/tinggi balok alginat dengan perobahan dimensi yang terjadi pada panjang dan lebarnya.

\section{Hasil penelitian}

Hasil pengukuran panjang, lebar dan tinggi/tebal sampel balok alginat hasil cetakan adalah dari hasil pengukuran pada panjang hasil cetakan terlihat pembesaran ukuran diantara $2,50-4,12 \%$ panjang dengan rerata $3,16 \%$ dan Standar deviasinya $0.63 \%$. (tabel 1)

Sedangkan dari hasil pengukuran pada lebar hasil cetakan terlihat pembesaran ukuran diantara 2,87-4,31\% panjang dengan rerata $3,35 \%$ dan SD 0,42\% (tabel 2).

Tabel 1. Hasil pengukuran pada panjang hasil cetakan

\begin{tabular}{|c|c|c|c|c|c|c|}
\hline Cetakan & $\begin{array}{l}\text { Panjang Die } \\
(\mathrm{mm})\end{array}$ & $\begin{array}{c}\text { Panjang Sampel } \\
(\mathrm{mm})\end{array}$ & $\begin{array}{l}\text { Beda panjang } \\
\text { (mm) }\end{array}$ & $\begin{array}{c}\text { Beda panjang } \\
\%\end{array}$ & $\chi$ & $\mathrm{SD}$ \\
\hline I & & 30,31 & $(+) 0,74$ & 2.50 & & \\
\hline II & & 30,73 & $(+) 1,16$ & 3,92 & & \\
\hline III & & 30,75 & (+) 1,18 & 3,99 & & \\
\hline IV & & 30,79 & (+) 1,22 & 4,12 & & \\
\hline V & 29,57 & 30,32 & $(+) 0,75$ & 2,53 & 3,16 & 0,63 \\
\hline VI & & 30,35 & $(+) 0,78$ & 2,63 & & \\
\hline VII & & 30,38 & $(+) 0,81$ & 2,73 & & \\
\hline VIII & & 30,40 & $(+) 0,83$ & 2,80 & & \\
\hline IX & & 30,43 & $(+) 0,92$ & 3,11 & & \\
\hline$X$ & & 30,49 & $(+) 0,98$ & 3,31 & & \\
\hline
\end{tabular}

Keterangan : (+) terjadi pembesaran ukuran.

Tabel 2. Hasil pengukuran pada lebar hasil cetakan

\begin{tabular}{ccccccc}
\hline Cetakan & $\begin{array}{c}\text { Panjang Die } \\
(\mathrm{mm})\end{array}$ & $\begin{array}{c}\text { Panjang Sampel } \\
(\mathrm{mm})\end{array}$ & $\begin{array}{c}\text { Beda lebar } \\
(\mathrm{mm})\end{array}$ & $\begin{array}{c}\text { Beda lebar } \\
\%\end{array}$ & $\chi$ & $\mathrm{SD}$ \\
\hline & & & & \\
I & & 20,07 & $(+) 0,62$ & 3,18 & & \\
II & 20,17 & $(+) 0,72$ & 3,70 & & \\
III & 20,29 & $(+) 0,84$ & 4,31 & & \\
IV & & 20,03 & $(+) 0,58$ & 2,98 & & \\
V & 19,45 & 20,01 & $(+) 0,56$ & 2,87 & 3,35 & 0,42 \\
VI & & 20,03 & $(+) 0,58$ & 2,98 & & \\
VII & 20,05 & $(+) 0,60$ & 3,08 & & \\
VIII & & 20,09 & $(+) 0,64$ & 3,29 & & \\
IX & 20,12 & $(+) 0,67$ & 3,44 & & \\
X & & 20,18 & $(+) 0,73$ & 3,75 & & \\
\hline
\end{tabular}

Keterangan : (+) terjadi pembesaran ukuran. 
Tabel 3. Hasil pengukuran pada tinggi/tebal hasil cetakan.

\begin{tabular}{ccccccc}
\hline Cetakan & $\begin{array}{c}\text { Panjang Die } \\
(\mathrm{mm})\end{array}$ & $\begin{array}{c}\text { Panjang Sampel } \\
(\mathrm{mm})\end{array}$ & $\begin{array}{c}\text { Beda tinggi } \\
(\mathrm{mm})\end{array}$ & $\begin{array}{c}\text { Beda tinggi } \\
\%\end{array}$ & $\chi$ & SD \\
\hline & & 10,61 & $(+) 0,94$ & 9,72 & & \\
I & & 10,81 & $(+) 1,14$ & 11,78 & & \\
II & & 10,84 & $(+) 1,17$ & 12,05 & & \\
III & & 10,88 & $(+) 1,21$ & 12,51 & & \\
IV & & 10,61 & $(+) 0,94$ & 9,72 & 10,87 & \\
V & 9,67 & 10,63 & $(+) 0,96$ & 9,92 & & \\
VI & & 10,65 & $(+) 0,98$ & 10,13 & & \\
VII & & 10,69 & $(+) 1,02$ & 10,54 & \\
VIII & & 10,72 & $(+) 1,05$ & 10,85 & & \\
IX & & 10,76 & $(+) 1,09$ & 11,27 & \\
X & & &
\end{tabular}

Keterangan : (+) terjadi pembesaran ukuran.

Dari hasil pengukuran pada tinggi/tebal hasil cetakan (tabel 3) terlihat pembesaran ukuran diantara 9,72 - 12,51\% panjang dengan rerata $10,87 \%$ dan SD $1,01 \%$

Dengan mempergunakan T-test (Paired Samples test) dalam uji statistiknya, terlihat bahwa ada perbedaan signifikan perobahan dimensi $(\mathrm{p}<0,05)$ pada tebal balok alginat yang dibatasi penutup lempengan kaca dibandingkan dengan perobahan dimensi pada panjang dan lebar balok alginat yang dikelilingi logam master die.

\section{PEMBAHASAN}

\section{Pengukuran yang sederhana dan langsung pada bahan cetak}

Dari prosedur percobaan di atas dapat terlihat simpulan dalam pelaksanaan dan pengamatan yang langsung dilakukan pada bahan cetak tanpa mempergunakan media lain (gips/die) dalam pengambilan ukurannya. Hal ini memudahkan pengambilan asumsi bahwa bila ada perobahan dimensi seperti yang terjadi pada percobaan ini, hal itu disebabkan dan terjadi pada bahan cetak itu sendiri.

\section{Perobahan dimensi.}

Pada percobaan ini terjadi perobahan dimensi pada setiap pengukuran baik panjang, lebar maupun tinggi/tebal balok bahan cetak. Perobahan itu berupa pembesaran ukuran dibandingkan dengan ukuran mold yang ada. Hasil ini mengingatkan bahwa telah terjadi ekspansi pada bahan cetak yang dipergunakan. Dari hasil pengukuran terlihat perobahan dimensi pada daerah tinggi/tebal balok alginat hasil cetakan jauh lebih besar (rerata 10,87\%) dibanding perobahan dimensi pada daerah panjang dan lebar hasil cetakan (rerata 3,16\% dan 3.35\% masing-masing). Pada daerah pengukuran tinggi/tebal bahan cetak, bahan cetak dibatasi dengan lempeng kaca yang pelepasannya dilakukan terlebih dahulu daripada daerah panjang dan lebar hasil cetakan yang dibatasi logam pembentuk mold.

\section{Kemungkinan penyebab perobahan dimensi.}

Pada bahan cetak hydrocolloids, Phillips dkk menyatakan bahwa perobahan dimensi dapat terjadi selama proses gelation berlangsung dengan adanya stres yang diberikan atau timbul pada bahan cetak sewaktu pengambilan cetakan. ${ }^{1}$ 
Hal ini juga sesuai dengan apa yang didapatkan oleh Masri dkk. yang dengan mempergunakan transducer pencatat tekanan (pressure) yang ditempatkan pada daerah tengah palatum dan daerah molar pertama kiri atas dan kanan mendapatkan bahwa semua bahan cetak yang dipergunakannya mengeluarkan tekanan (pressure) sewaktu pengambilan cetakan rahang atas tak bergigi. ${ }^{13}$

Pada percobaan kali ini terlihat adanya perbedaan yang signifikan diantara perobahan dimensi yang terjadi pada tinggi/tebal balok alginat yang dibatasi lempengan kaca dibandingkan dengan perobahan dimensi yang terjadi pada panjang maupun lebar balok alginat. Walaupun demikian adanya perbedaan perobahan dimensi yang signifikan tersebut belum dapat dikatakan disebabkan oleh adanya tekanan (pressure) yang terjadi didalam bahan cetak yang timbul sewaktu pembuatan balok alginat yang akan memberi efek pada bahan cetak sewaktu pelepasan lempeng kaca dan master die dan menyebabkan terjadinya ekspansi pada bahan cetak. Hal ini masih memerlukan pengamatan dan pembuktian lebih lanjut.

\section{SIMPULAN}

Dari percobaan mengenai perobahan dimensi hasil cetakan berbentuk balok atas dapat disimpulkan bahwa perobahan dimensi yang terjadi pada penggunaan bahan cetak dapat disebabkan oleh dan terjadi pada bahan cetak yang dipergunakan itu sendiri.

\section{SARAN}

Pada pengamatan kali ini belum dapat dijelaskan penyebab terjadinya perobahan dimensi pada bahan cetak yang dipergunakan. Hal ini mengharuskan adanya pengamatan lebih lanjut agar dapat diperoleh keakuratan hasil cetakan alginat.

\section{Ucapan terima kasih}

Penulis ingin menyampaikan rasa terima kasih yang sebesar-besarnya kepada sdr. Mulyadi yang telah banyak membantu dalam keseluruhan pekerjaan sehingga memungkinkan makalah ini dituliskan.

\section{Daftar Pustaka}

1. Phillips RW. Skinner's science of dental materials. 8th Ed. Philadelphia: WB Saunders Co.; 1982. p. 108-36.

2. Sawyer HF. Accuracy of casts produced from alginate and hydrocolloid impression materials. J Am Dent Assoc 1976; 93: 806-8.

3. Linke BA. Distortion analysis of stone casts made from impression materials. J Prosthet Dent 1985; 54 (6): 794-802.

4. Thongthammachat S. Dimensional accuracy of dental casts: influence of tray material, impression material and time. J Prosthodont 2002 Jun; 11 (2): 98-108.

5. Daoudi MF. A laboratory investigation of the accuracy of two impression techniques for single-tooth implants. Int J Prosthodont 2001; 14 (2): $152-8$.

6. Fenske C. The influence of five impression techniques on the dimensional accuracy of master models. Braz Dent J 2000; 11 (1): 1927.

7. Larson TD. The accuracy of dual-arch impressions: a pilot study. J Prosthet Dent 2002; 87 (6): 625-7.

8. De Araujo PA, Jorgensen KD. Effect of material bulk and undercuts on the accuracy of impression materials. J Prosthet Dent 1985; 54 (6): 791-4.

9. Eames WB. Elastomeric impression materials: effect of bulk on accuracy. J Prosthet Dent 1979; 41 (3): 304-7.

10. Wee AG. Accuracy of 3 conceptually different die systems used for implant casts. J Prosthet Dent 2002; 87 (1): 23-9. 
11. Bloem TJ. Determination of the accuracy of three die systems. J Prosthet Dent 1991; 65: 758-62.

12. Rusfian, Sumadhi S, Muldiat, Eviyati, Lasminda Sy, Chadijah S. Pengukuran perobahan dimensi pada model dental stone disebabkan oleh perobahan temperatur dan
W/P ratio. Kumpulan Makalah Ilmiah Peringatan HUT ke 25 FKG-USU; 1986. p.80-3.

13. Masri R. Pressure generated on a simulated oral analog by impression materials in custom trays of different design. J Prosthodont 2002; 11(3): 155-60. 